\title{
PENINGKATAN KOMPETESI MELALUI SELF-CONCEPT PARA PENGRAJIN TAHU TEMPE PRIMKOPTI SWAKERTA, SEMANAN JAKARTA BARAT
}

\author{
Deasy Aseanty ${ }^{1}$, Eko Retno Indriyarti ${ }^{2)}$, Tiara Puspa ${ }^{3)}$ Justine Tanuwijaya $^{4)}$, Nurhastuty \\ Kesumo $^{5)}$, Audita Setiawan', Gunarto ${ }^{7)}$ \\ 1,2,3,4,5,6,7)Fakultas Ekonomi dan Bisnis, Universitas Trisakti
}

Diterima 8 Agustus 2021 / Disetujui 26 Agustus 2021

\begin{abstract}
The decline in the turnover of tofu and tempe craftsmen in the Semanan area, Kali Deres sub-district, West Jakarta, has caused the tofu and tempeh craftsmen to have to think of strategies to keep their production running and increase sales. In addition, craftsmen are forced to reduce the amount of production compared to usual to prevent oversupply due to a decrease in demand. In addition, the price of the tofu and tempe was also increased from usual to cover the losses received. Among the various factors that can cause it, one important factor is increasing the competence of craftsmen through self-concept. This aspect concerns the positive values and attitudes of tofu and tempeh craftsmen related to the business. The community service carried out aims to increase competence through self-concept in the tofu and tempeh craftsman group in this region. The community service method is carried out using online counseling by providing material and question and answer $(Q \& A)$ discussions. The service was carried out smoothly. The measurement of the effectiveness of this abdimas uses a simple descriptive-quantitative by explaining the increase in insight into the competence of the craftsmen in terms of self-concept. In addition, the results of the service carried out were able to provide increased insight into tofu and tempe craftsmen in this region regarding self-concept-based competencies. The most significant improvement was found on a fairly good achievement scale (from 0\% to 48\%) where 5-6 items were answered correctly by the participants. The importance of the ability to manage creative marketing and sales strategies by utilizing online (digital) media is a recommendation for the next abdimas topic.
\end{abstract}

Keywords: self-concept, competence, entrepreneurship, tofu, tempe

\begin{abstract}
ABSTRAK
Penurunan omset pengrajin tahu tempe di daerah Semanan Kecamatan Kali Deres, Jakarta Barat menyebabkan pengrajin tahu tempe ini harus memikirkan strategi guna mempertahankan produksinya agar terus berjalan, serta meningkatkan penjualan. Selain itu, pengrajin dipaksa untuk mengurangi jumlah produksi dibanding biasanya untuk mencegah terjadinya over supply karena adanya penurunan permintaan. Selain itu, harga dari tahu tempe tersebut juga dinaikan dari biasanya guna menutup kerugian yang diterima. Di antara beragamnya faktor yang dapat menyebabkan, salah satu faktor penting adalah meningkatkan kompetensi pengrajin melalui self-concept. Aspek ini menyangkut nilai dan sikap positif yang ada pada diri pengrajin tahu tempe terkait dengan bisnis yang dijalankannya.
\end{abstract}

*Korespondensi Penulis:

E-mail: ekoretno@trisakti.ac.id 
Pengabdian kepada masyarakat (abdimas) yang dilakukan bertujuan untuk meningkatkan kompetensi melalui self-concept pada kelompok pengrajin tahu tempe di wilayah ini. Metode abdimas dilakukan menggunakan penyuluhan daring dengan memberikan materi dan diskusi tanya jawab. Pengabdian yang dilakukan berjalan lancar. Pengukuran efektivitas abdimas ini menggunakan deskriptif-kuantitatif sederhana dengan menjelaskan peningkatan wawasan kompetensi pengarajin dalam hal self-concept. Selain itu, hasil abdimas yang dilakukan mampu memberikan peningkatan wawasan pengrajin tahu tempe di wilayah ini mengenai kompetensi berbasis self-concept. Peningkatan yang paling siginifikan terdapat pada skala capaian cukup baik (dari 0\% menjadi 48\%) dimana 5-6 item dijawab dengan benar oleh para peserta. Pentingnya kemampuan dalam mengelola strategi pemasaran dan penjualan yang kreatif dengan memanfaatkan media daring (digital) menjadi rekomendasi topik abdimas selanjutnya.

Kata Kunci: konsep diri, kompetensi, wirausaha, tahu, tempe

\section{PENDAHULUAN}

Setiap orang berkesempatan menjadi seorang wirausahawan agar dapat menjalankan bisnis, walau keinginan dan kemauan saja tidak cukup. Ada beberapa hal lainnya yang perlu diperhatikan sekaligus dimiliki oleh wirausahawan. Wirausahawan dapat dijelaskan sebagai individu atau kelompok yang melakukan usaha, mengorganisir, mengumpulkan modal pembiayaan, dan mengestimasi risiko. Risiko dalam hal ini dapat berbentuk kondisi pasar (Cahya \& Christian, 2020; Santosa \& Christian, 2017) dimana berkaitan dengan selera masyarakat (konsumen). Secara definisi, wirausahawan tidak terlepas dari definisi bisnis (khususnya usaha mikro, kecil dan menengah) yang berorientasi pada profit (Bamfo \& Kraa, 2019; Hassen \& Singh, 2020; Khan, Salamzadeh, Kawamorita, \& Rethi, 2021)

Kompetensi dapat berbentuk
pengetahuan atau keterampilan serta kemampuan individu yang berkaitan terhadap kinerja. Wirausahawan akan memiliki peluang lebih besar untuk bisa bersaing apabila memiliki aspek-aspek tersebut. Lebih lanjut, hal ini berfungsi untuk kemampuan mengenali bisnis yang dilakukan, manajemen bisnis, sikap, modal, dan kemampuan untuk mengatur waktu dengan baik. Selain itu, kemampuan ini berfungsi untuk aspek kemampuan dalam mengelola tim, membentuk kepuasan pelanggan ataupun bersaing. Individu memiliki kompetensi sepanjang sudah terbentuknya kemauan dan komitmen (Jansson, Nilsson, Modig, \& Vall, 2017; Mukson, Hamidah, \& Prabuwono, 2019; Salisu \& Bakar, 2019). Kompetensi yang dimiliki wirausahawan sangat berpengaruh pada keberlanjutan bisnisnya.
Kompetensi ini diperlukan dalam segala situasi, termasuk di era pandemi COVID-19 ini. Di saat banyak perusahaan atau bisnis yang menghentikan bsinisnya atau memberhentikan karyawannya, namun masih ada bisnis yang tetap berjalan, walau dengan melakukan serangkaian penyesuaian atau telah melakukan beberapa perubahan untuk menyesuaikan dengan situasi yang terjadi. Segala penyesuaian atau perubahan tersebut dapat terjadi apabila orang-orangnya memiliki salah satu faktor, yaitu kompetensi.

Terdapat beberapa aspek dari kompetensi, yaitu salah satunya adalah selfconcept (Deniz \& Yozgat, 2013; Johar, Yusoff, \& Ismail, 2018; Puente-Palacios \& Souza, 2018; Sadough \& Ebrahimi, 2015) yang terdiri dari sikap dan nilai positif dari wirausahawan menghadapi situasi apapun terkait dengan bisnis yang dijalankan. Sikap merupakan pernyataan evaluatif yang baik maupun tidak baik terhadap sebuah obyek, kejadian, atau orang. Sedangkan nilai merupakan keyakinan dasar bahwa model perilaku tertentu atau kondisi akhir keberadaan secara pribadi atau sosial lebih disukai daripada model perilaku yang berlawanan. Apabila wirausahawan memiliki aspek ini, maka diharapkan akan membantu meningkatkan kompetensi demi menunjang keberhasilan bisnis.

Begitu pula dengan yang ada di sebuah kelurahan Semanan, Jakarta Barat, dimana banyak ditemukan pengrajin tahu tempe. Kelompok ini menjalankan usahanya untuk memproduksi tahu tempe. Namun situasi pandemi ini tentu berpengaruh kepada usaha ini. Biasanya tempe tahu itu sampai ke pasar dan terjual dengan jumlah yang banyak. Namun, pandemi menyebabkan adanya penurunan penjualan yang berdampak pada penurunan pendapatan. Hal ini membuat 
kelompok usaha ini harus berpikir keras dalam menghadapi tantangan bagaimana agar produksi dan penjualan meningkat, tingkat pendapatan juga meningkat. Berdasarkan informasi wawancara lokadata dengan pengrajin di wilayah ini, permintaan menurun dari sebelum masa pandemi sebanyak 80-90 $\mathrm{kg}$ menjadi $20 \mathrm{~kg}$ (awal masa pandemi) dan $50 \mathrm{~kg}$ (masa pandemi) (Firmansyah, 2020).

Seperti yang dihadapi usaha lainnya di masa pandemic COVID-19 (Christian et al., 2021), masalah yang dihadapi bagi para pengrajin tahu tempe juga berkaitan erat dengan penurunan tingkat pendapatan para pengrajin sehingga perlu meningkatkan kompetensi para pengrajin khususnya aspek self-concept agar dapat meningkatkan keberhasilan usahanya. Berdasarkan informasi yang diperoleh dari survey terdahulu dan dari beragam sumber lainnya, masalah utama adalah tentang self-concept atau pemahaman diri. Self-Concept dapat mendukung keberhasilan tujuan yang ingin dicapai (Abbassi \& Sta, 2019; Ayalew \& Zeleke, 2018). Self-Concept merupakan landasan untuk dapat menyesuaikan diri, dan terbentuk karena suatu proses umpan balik dari individu yang lain. Agar para pemilik usaha tahu tempe Semanan memahami tentang pemahaman diri atau self-concept maka kegiatan pengabdian kepada masyarakat (abdimas) dilaksanakan dengan Pemberdayaan aspek self-concept untuk meningkatkan kompetensi dalam menunjang keberhasilan bisnis. Akhir-akhir ini beberapa kegiatan abdimas mengenai pentingnya peningkatan kompetensi dalam usaha/bisnis melalui beberapa publikasi kegiatan abdimas seperti ditunjukan pada tabel 1 .

Tabel 1. Publikasi Pelaksanaan Abdimas Peningkatan Kompetensi

\begin{tabular}{|c|c|c|c|c|}
\hline Penulis & Lokasi & Kompetensi & Peserta Abdimas & Metode \\
\hline $\begin{array}{l}\text { Handayani et al., } \\
(2021)\end{array}$ & $\begin{array}{l}\text { Pangkalan Jati, } \\
\text { Jakarta Selatan }\end{array}$ & $\begin{array}{l}\text { Peningkatan value-added } \\
\text { produk }\end{array}$ & $\begin{array}{l}\text { Usaha mikro } \\
\text { tekstil }\end{array}$ & $\begin{array}{l}\text { Penyuluhan } \\
\text { daring }\end{array}$ \\
\hline $\begin{array}{l}\text { Rizianiza et al., } \\
(2021)\end{array}$ & $\begin{array}{l}\text { Kabupaten } \\
\text { Penajam Paser } \\
\text { Utara, } \\
\text { Kalimantan } \\
\text { Timur }\end{array}$ & $\begin{array}{l}\text { Peningkatan desain kemasan } \\
\text { produk }\end{array}$ & $\begin{array}{l}\text { Kelompok } \\
\text { pengolah rumput } \\
\text { laut }\end{array}$ & $\begin{array}{l}\text { Penyuluhan dan } \\
\text { pendampingan }\end{array}$ \\
\hline $\begin{array}{l}\text { Suwardi et al., } \\
(2021)\end{array}$ & $\begin{array}{l}\text { Desa } \\
\text { Matang } \\
\text { Gleum, Aceh } \\
\text { Timur }\end{array}$ & $\begin{array}{l}\text { Peningkatan strategi } e \text { - } \\
\text { marketing }\end{array}$ & $\begin{array}{l}\text { Kelompok } \\
\text { produksi tenun lidi } \\
\text { nipah }\end{array}$ & Pelatihan \\
\hline $\begin{array}{l}\text { Utama et al., } \\
(2021)\end{array}$ & $\begin{array}{l}\text { Bangka Tengah, } \\
\text { Bangka Belitung }\end{array}$ & $\begin{array}{l}\text { Peningkatan keterampilan dan } \\
\text { pengetahuan komersialisasi } \\
\text { madu dan propolis }\end{array}$ & $\begin{array}{l}\text { Kelompok tani } \\
\text { hutan }\end{array}$ & $\begin{array}{l}\text { Pelatihan dan } \\
\text { pemantauan }\end{array}$ \\
\hline $\begin{array}{l}\text { Iftitah et al., } \\
(2021)\end{array}$ & $\begin{array}{l}\text { Kelurahan } \\
\text { Kedungsari, } \\
\text { Magelang } \\
\end{array}$ & $\begin{array}{l}\text { Peningkatan wawasan dan } \\
\text { keterampilan perbanyakan } \\
\text { tanaman hias secara vegetatif }\end{array}$ & $\begin{array}{l}\text { Kelompok } \\
\text { pemberdayaan } \\
\text { perempuan }\end{array}$ & $\begin{array}{l}\text { Penyuluhan, } \\
\text { pelatihan, } \\
\text { pendampingan }\end{array}$ \\
\hline $\begin{array}{l}\text { Uliyandari et al., } \\
(2021)\end{array}$ & $\begin{array}{l}\text { Kelurahan } \\
\text { Sumber Jaya, } \\
\text { Bengkulu }\end{array}$ & $\begin{array}{l}\text { Meningkatkan produktivitas } \\
\text { pupuk kompos bioaktivator } \\
\text { dengan bahan baku limbah } \\
\text { organik rumah tangga }\end{array}$ & $\begin{array}{l}\text { Kelompok wanita } \\
\text { tani }\end{array}$ & $\begin{array}{l}\text { Penyuluhan, } \\
\text { monitoring, } \\
\text { evaluasi }\end{array}$ \\
\hline $\begin{array}{l}\text { Sundara et al., } \\
(2020)\end{array}$ & $\begin{array}{l}\text { Jagakarsa, Jakarta } \\
\text { Selatan }\end{array}$ & $\begin{array}{l}\text { Peningkatan etika bisnis dan } \\
\text { kewirausahaan melalui } \\
\text { sosialiasi }\end{array}$ & $\begin{array}{l}\text { Usaha mikro kecil } \\
\text { menengah situ } \\
\text { babakan }\end{array}$ & $\begin{array}{l}\text { Sosialisasi dan } \\
\text { evaluasi } \\
\text { pengetahuan }\end{array}$ \\
\hline $\begin{array}{l}\text { Anggoro et al., } \\
(2020)\end{array}$ & $\begin{array}{l}\text { Purwakarta, Jawa } \\
\text { Barat }\end{array}$ & $\begin{array}{l}\text { Peningkatan pemasaran dan } \\
\text { penjualan dengan digital } \\
\text { marketing }\end{array}$ & $\begin{array}{l}\text { Usaha kecil } \\
\text { menengah garasi } \\
\text { kayu }\end{array}$ & $\begin{array}{l}\text { Instalasi dan } \\
\text { pelatihan }\end{array}$ \\
\hline Ajibulloh (2020) & Nasional & $\begin{array}{l}\text { Peningkatan kemampuan } \\
\text { digital marketing melalui } \\
\text { pemanfaatan Microsoft } \\
\text { Powerpoint }\end{array}$ & $\begin{array}{l}\text { Pelaku usaha kecil } \\
\text { mikro kecil } \\
\text { menengah secara } \\
\text { umum }\end{array}$ & Pelatihan \\
\hline $\begin{array}{l}\text { Pratama et al., } \\
(2020)\end{array}$ & $\begin{array}{l}\text { Desa Wonoayu, } \\
\text { Malang }\end{array}$ & $\begin{array}{l}\text { Peningkatan wawasan } \\
\text { mengenai permodalan usaha } \\
\text { melalui fintech lending }\end{array}$ & $\begin{array}{l}\text { Pelaku usaha } \\
\text { mikro, kecil, } \\
\text { menengah di desa }\end{array}$ & Semi-webinar \\
\hline
\end{tabular}


Sehubungan dengan penjelasanpenjelasan analisis situasi di atas, tim Pengabdian Kepada Masyarakat (Abdimas) Fakultas Ekonomi dan Bisnis Universitas (FEB) Trisakti, bermaksud untuk melaksanakan kegiatan pengabdian kepada masyarakat, yang bertujuan untuk membantu para pengrajin tahu tempe di kelurahan Semanan dalam bentuk kegiatan penyuluhan agar dapat meningkatkan kompetensi khususnya aspek self-concept terutama di era pandemi COVID19, demi menunjang keberhasilan bisnis.

\section{METODE}

Abdimasi ini dilakukan dengan melakukan observasi kebutuhan pengrajin tahu tempe di lokasi. Selanjutnya tim
Abdimas FEB Trisakti membuat konsep perencanaan teknis abdimas yang akan diberikan (tabel 2). Abdimas ini dilaksanakan dengan metode penyuluhan secara daring menggunakan media ZOOM dari tanggal 1618 Maret 2021. Pengukuran efektivitas abdimas ini dilakukan dengan menggunakan kuesioner. Pada kegiatan ini terdapat 25 peserta abdimas yang berasal dari pengrajin tahu tempe di wilayah Semanan, Jakarta Barat. Kuesioner didesain dengan menggunakan 10 item wawasan umum berbasis self-concept dan kompetensi yang dibentuk dari dimensi pengetahuan yang bersifat kognitif, harapan (self-ideal), dan penilaian diri sendiri. Skala ukur dari item ini diukur dengan "Ya" dan "Tidak". Kuesioner ini diberikan dalam 2 sesi yaitu pre-test dan post-test. Analisis efektivitas abdimas ini menggunakan statistik deskriptif.

Tabel 2. Konsep Perencanaan Abdimas

\begin{tabular}{|c|c|c|c|c|}
\hline No & Rincian & & Ketua & Tim \\
\hline \multirow[t]{9}{*}{1} & \multicolumn{4}{|l|}{ Survey Pendahuluan } \\
\hline & a Pengumpulan info tentang objek PKM beragam Media & & $\sqrt{ }$ & $\sqrt{ }$ \\
\hline & Penyusunan List masalah SDM objek PKM & & $\sqrt{ }$ & $\sqrt{ }$ \\
\hline & Penyusunan list pertanyaan tentang pemahaman diri & Dokumen & $\sqrt{ }$ & $\sqrt{ }$ \\
\hline & Observasi lokasi produksi & Survey, Foto & $\sqrt{ }$ & $\sqrt{ }$ \\
\hline & Observasi lokasi gudang kedelai mentah & aktivitas, & $\sqrt{ }$ & $\sqrt{ }$ \\
\hline & Wawancara dengan subjek pengrajin tahu tempe & Produksi, Foto & $\sqrt{ }$ & $\sqrt{ }$ \\
\hline & Wawancara dengan ketua pengurus koperasi & aset produksi & $\sqrt{ }$ & $\sqrt{ }$ \\
\hline & $\begin{array}{l}\text { h Dokumentasi aktivitas produksi, ragam jenis aset tetap, } \\
\text { hasil wawancara }\end{array}$ & & $\sqrt{ }$ & $\sqrt{ }$ \\
\hline \multirow[t]{4}{*}{2} & \multicolumn{4}{|l|}{ Penyusunan proposal } \\
\hline & a Diskusi draf proposal PKM & Proposal & $\sqrt{ }$ & \\
\hline & Pengumpulan kelengkapan dokumen proposal & PKM & $\sqrt{ }$ & \\
\hline & c Upload proposal ke SIMPPT & terunggah & $\sqrt{ }$ & \\
\hline \multirow[t]{4}{*}{3} & Penyusunan Materi PKM dan Kuesioner Umpan Balik & \multirow{4}{*}{$\begin{array}{c}\text { Modul PKM } \\
\text { PPT PKM }\end{array}$} & & \\
\hline & a Diskusi materi PKM & & $\sqrt{ }$ & $\sqrt{ }$ \\
\hline & Penyusunan PPT & & $\sqrt{ }$ & $\sqrt{ }$ \\
\hline & c Penyusunan kuesioner umpan balik & & $\sqrt{ }$ & $\sqrt{ }$ \\
\hline \multirow[t]{5}{*}{4} & \multicolumn{4}{|l|}{ Pelaksanaan PKM } \\
\hline & a $\quad$ Penyajian materi (PPT) & Dokumen & & $\sqrt{ }$ \\
\hline & Diskusi Tanya jawab dengan peserta PKM & pelaksana & $\sqrt{ }$ & $\sqrt{ }$ \\
\hline & Pengumpulan Kuesioner Umpan balik & PKM, Link & $\sqrt{ }$ & $\sqrt{ }$ \\
\hline & Mendokumentasikan pelaksanaan PKM & Zoom & $\sqrt{ }$ & $\sqrt{ }$ \\
\hline
\end{tabular}

Sumber: diolah penulis

HASIL DAN PEMBAHASAN
Kegiatan abdimas dilaksanakan dengan lancar dimana proses penyampaian materi penyuluhan peningkatan kompetensi 
berbasis self-concept diberikan melalui beberapa sajian materi presentasi yang diberikan oleh beberapa pembicara dari tim abdimas FEB Trisakti (gambar 1).
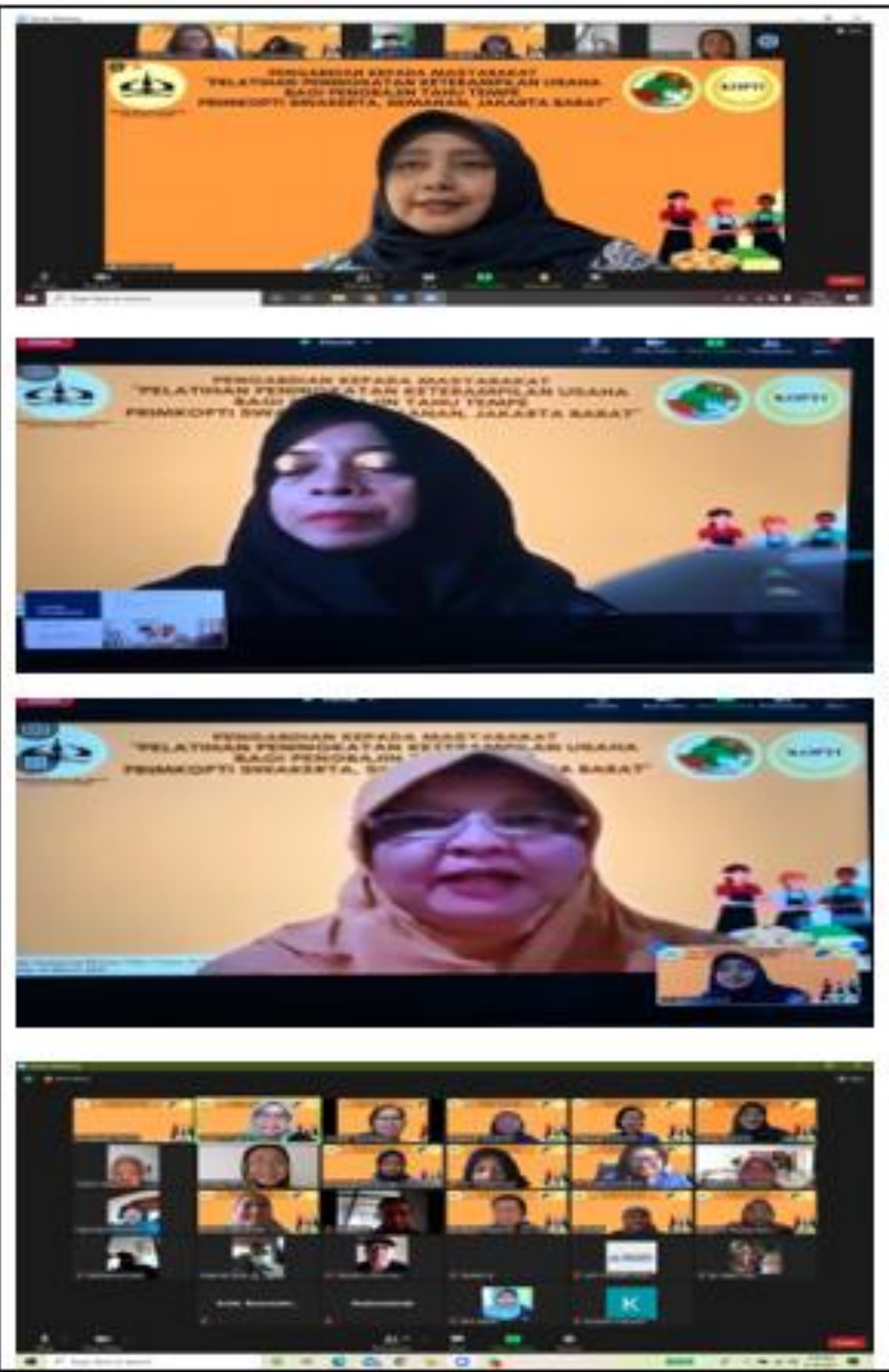

Gambar 1. Penyampaian materi penyuluhan abdimas

Keberhasilan sebuah program diukur dari adanya perbedaan kinerja sebelum dan setelah pelatihan dilakukan. Pengukuran kinerja ini diperlukan untuk memastikan manfaatnya serta tindakan koreksi yang diperlukan pada tahap selanjutnya. Demikian juga dengan aktivitas PKM ini. Tim PKM menyusun pretest yang disampaikan kepada 
para peserta untuk diisi. Hasil pengukuran efektivitas abdimas ini melalui kuesioner wawasan peserta mengenai kompetensi berbasis self-concept ditunjukan pada tabel 3 .

Tabel 3. Pengukuran Abdimas

\begin{tabular}{llllll}
\hline \multirow{2}{*}{$\begin{array}{l}\text { Jumlah } \\
\text { jawaban benar }\end{array}$} & \multirow{2}{*}{ Skala capaian } & \multicolumn{3}{c}{ Hasil (n=25; 100\%) } \\
\cline { 3 - 6 } & & Pre-test & \multicolumn{2}{l}{ Post-test } \\
\hline Tidak ada (0) & Sangat buruk & 7 & $28 \%$ & 0 & $0 \%$ \\
\hline 1 hingga 2 & Buruk & 11 & $44 \%$ & 0 & $0 \%$ \\
\hline 3 hingga 4 & Kurang & 6 & $24 \%$ & 3 & $12 \%$ \\
\hline 5 hingga 6 & Cukup baik & 0 & $0 \%$ & 12 & $48 \%$ \\
\hline 7 hingga 8 & Baik & 1 & $4 \%$ & 7 & $28 \%$ \\
\hline 9 hingga 10 & Sangat baik & 0 & $0 \%$ & 3 & $12 \%$ \\
\hline
\end{tabular}

Sumber: diolah penulis

Berdasarkan jawaban responden pada sesi pre-test (tabel 3), hanya $4 \%$ saja yang mampu menjawab 7 hingga 8 dengan benar. Sebanyak $44 \%$ peserta pelatihan menjawab 1 hingga 2 pertanyaan saja, $28 \%$ tidak ada jawaban yang benar dan $28 \%$ mampu menjawab benar 3 hingga 4 pertanyaan. Dari hasil sesi ini dapat dijelaskan bahwa mayoritas peserta abdimas kurang memiliki/mendapatkan wawasan atau pengetahuan mengenai kompetensi berbasis self-concept untuk mengembangkan suatu unit usaha. Oleh karena itu, penyuluhan melalui abdimas ini dinilai tepat untuk meningkatkan kompetensi berbasis selfconcept pada pengrajin tahu tempe di wilayah ini. Selanjutnya setelah penyuluhan dilakukan pengukuran lagi melalui kuesioner yang sama kepada para peserta abdimas. Berdasarkan hasil pada tabel 3 menunjukan bahwa mayoritas peserta telah menjawab dengan benar (48\%), bahkan $28 \%$ masuk dalam skala kriteria capaian baik dan $12 \%$ masuk dalam kriteria capaian sangat baik. Hasil pengukuran ini juga menjelaskan bahwa kegiatan ini dapat dikatakan efektif dalam meningkatkan pengetahuan pengrajin tahu tempe di wilayah ini khususnya dalam membangun nilai personal dalam selfconcept, misalnya semakin memiliki tanggung jawab untuk mencari strategi untuk penjualan tahu tempe, dapat membentuk sikap antusias terhadap permasalahan yang ada di masa pandemi dan semakin memiliki rasa tanggung jawab atas penjualan tahu tempe di masa pandemi. Aspek-aspek ini kurang terbentuk bagi pengarajin tahu tempe di wilayah ini sebelum pandemi sampai sebelum abdimas ini dilakukan. Kondisi yang sulit dan kompleks selama pandemi membuat pengrajin semakin terpuruk sehingga dengan adanya abdimas ini dapat memberikan kontribusi pada aspek-aspek yang telah dijelaskan sebelumnya.

Dalam menjalankan bisnis, diperlukan beberapa karakteristik yang harus dimiliki oleh wirausahawan, seperti: memiliki keterampilan personal, realistis dan mandiri, kreatif dan inovatif, disiplin, jujur, serta berkomitmen tinggi. Karakteristik tersebut sangat diperlukan mengingat sebuah bisnis memerlukan perencanaan yang matang dan fokus dan ketelitian yang mendalam agar bsnis bisa dijalankan dengan baik. Sebuah bisnis diharapkan juga dapat berkembang, seiring dengan apa yang sudah dijalankan oleh wirausahawan, walau dalam menjalankannya wirausahawan pasti akan menghadapi segala resiko, namun dengan keterampilan dalam menangani resiko, maka bisnis akan tetap dipertahankan. Hasil pengukuran pada abdimas ini juga sejalan dengan konsep dari beberapa hasil penelitian yang juga mengkaitkan adanya peran serta self-concept dalam berjalannya suatu usaha/bisnis pada berbagai skala (Abbassi \& Sta, 2019; Jansson et al., 2017; PuentePalacios \& Souza, 2018).

Seiring dengan situasi saat ini, dimana pandemi telah menyebabkan perubahan pada banyak hal, serta terganggunya kegiatan bisnis. Beberapa kegiatan bisnis collapse, meskipun masih ada kegiatan bisnis yang tetap bisa bertahan untuk terus dijalankan, namun harus dengan melakukan banyak perubahan dan penyesuaian, dan yang pasti tidak mudah bagi wirausahawan untuk tetap bertahan di situasi begini. Pemerintah juga banyak menerapkan aturan baru. Sehingga wirausahawan sangat perlu untuk meningkatkan kompetensi untuk menata kembali bisnis yang sudah dijalankan. Wirausahawan merupakan bagian dari Sumber Daya Manusia, yang mana 
keberadaannya sangat penting baik untuk menjalanakan bisnis, mengembangkan bisnisnya, dan memastikan adanya bisnis yang berkelanjutan. Tanggung jawab wirausahawan sangat besar sekali. Oleh sebab itu, seorang wirausahawan juga perlu memiliki kompetensi yang akan dapat menunjang keberhasilan dari usahanya.

\section{SIMPULAN}

Abdimas yang dilakukan oleh tim pelaksana dari FEB Universitas Trisakti dapat dikatakan berjalan dengan lancar dan memberikan efektivitas terhadap peningkatan wawasan peserta terhadap kompetensi berbasis self-concept dalam usaha. Berdasarkan pengukuran efektivitas wawasan peserta terhadap kompetensi berbasis selfconcept, dijelaskan bahwa pada skala capaian sangat buruk terjadi peningkatan wawasan dari pre-test dan post-test dimana sudah tidak ada peserta yang tidak menjawab. Pada skala capaian buruk juga telah terjadi peningkatan wawasan yang siginifikan dimana dari $44 \%$ yang hanya menjawab 1 pertanyaan dengan benar menjadi $0 \%$ pada saat post-test. Selanjutnya pada skala capaian kurang juga mengalami peningkatan wawasan yang tinggi dimana capaian $24 \%$ pada sesi pre-test berkurang menjadi $12 \%$ pada sesi post-test. Pada kelompok capaian positif dimana skala capaian cukup baik juga terjadi peningkatan wawasan peserta mengenai kompetensi selfconcept, dimana $0 \%$ pada saat pre-test meningkat siginifikan menjadi $48 \%$ pada sesi post-test. Selanjutnya pada skala capaian baik perubahan juga terjadi dari $4 \%$ menjadi $28 \%$. Pada skala capaian terakhir yaitu sangat baik, peningkatan wawasan peserta sebesar $12 \%$ juga berhasil dibentuk. Kondisi pandemic COVID-19 yang memberikan pembatasan di berbagai aspek termasuk keterjangkauan peserta dengan tim menjadikan kegiatan abdimas ini dilakukan secara daring. Kebutuhan para peserta tidak hanya berhenti sebatas peningkatan pada wawasan kompetensi berbasis self-concept saja. Aspek kreativitas penjualan secara daring untuk produk tahu tempe juga menjadi rekomendasi di pelaksanakan abdimas selanjutnya. Aspek ini menjadi sangat penting di masa pandemi dimana pembatasan sosial menjadi aspek peluang untuk melakukan pemasaran atau penjualan secara daring.

\section{DAFTAR PUSTAKA}

Abbassi, R., \& Sta, N. (2019). The Effect of self-esteem, entrepreneurship education, and entrepreneurial tradition of the family on the entrepreneurial intention among students. Journal of Business and Management Research, 12, 235245.

Ajibulloh, A. A. (2020). Pemanfaatan Microsoft Powerpoint Sebagai Solusi Strategi Visual Digital Marketing Untuk UMKM di Masa Pandemi. SELAPARANG. Jurnal Pengabdian Masyarakat Berkemajuan, 4(1), 474478.

Anggoro, D., Hasugian, H., \& Nofiyanti, N. (2020). Implementasi Digital Marketing Pada UKM Guna Meningkatkan Pemasaran dan Penjualan Produk Di Masa Pandemi Covid-19. JURPIKAT(Jurnal Pengabdian Kepada Masyarakat), 1(3), 384-391. https://doi.org/10.37339/jurpikat.v1i3.3 45

Ayalew, M. M., \& Zeleke, S. A. (2018). Modeling the impact of entrepreneurial attitude on self-employment intention among engineering students in Ethiopia. Journal of Innovation and Entrepreneurship, 7(8), 1-27. https://doi.org/10.1186/s13731-0180088-1

Bamfo, B. A., \& Kraa, J. J. (2019). Market orientation and performance of small and medium enterprises in Ghana: The mediating role of innovation. Cogent Business \& Management, 6(1605703), $1-16$.

https://doi.org/10.1080/23311975.2019. 1605703

Cahya, K. O., \& Christian, M. (2020). Determinan Kinerja Usaha Mikro Kecil Menengah (Umkm) Alat Teknik di Pasar HWI Lindeteves Jakarta. Jurnal Pengabdian Dan Kewirausahaan, 4(2), 121-128. https://doi.org/10.30813/jpk.v4i2.2330

Christian, M., Dewi, D., Rembulan, G. D., Indriyarti, E. R., Wibowo, S., \& 
Yuniarto, Y. (2021). Business Performance Determinants of Salted Fish Distribution in Kapuk During the COVID-19. Journal of Distribution Science, 19(6), 29-39. https://doi.org/10.15722/jds.19.6.20210 6.29

Deniz, R. B., \& Yozgat, U. (2013). The effects of self-concept connection, partner quality and trust on commitment in the elderly segment. Procedia Social and Behavioral Sciences, 99, 403-412.

Firmansyah, L. M. (2020). Kembang kempis perajin tempe tahu di masa pagebluk. Retrieved from lokadata website: https://lokadata.id/artikel/kembangkempis-perajin-tempe-tahu-di-masapagebluk

Handayani, T., Rahmi, M., \& Fathoni, M. A. (2021). Pemberdayaan Pelaku Ekonomi Usaha Mikro Terdampak Covid-19 di Kelurahan Pangkalan Jati Jakarta Selatan. IKRAITH-ABDIMAS, 4(2), 613.

Hassen, Y., \& Singh, A. (2020). The Effect of Market Orientation on the Performance of Small and Medium Enterprises in Case of Amhara Region, Ethiopia. Journal of New Business Ventures, 1(12), $92-109$. https://doi.org/10.1177/2632962X20961 051

Iftitah, S. N., Masithoh, R. F., Pramesti, D. A., \& Basri, B. (2021). Pelatihan Perbanyakan Tanaman Hias Secara Vegetatif. CARADDE: Jurnal Pengabdian Kepada Masyarakat, 3(3), 467-473. https://doi.org/10.31960/caradde.v3i3.7 29

Jansson, J., Nilsson, J., Modig, F., \& Vall, G. H. (2017). Commitment to Sustainability in Small and MediumSized Enterprises: The Influence of Strategic Orientations and Management Values. Business Strategy and the Environment, 26, 69-83. https://doi.org/10.1002/bse.1901

Johar, S. S., Yusoff, R. M., \& Ismail, F. (2018). Self-Esteem Impact on
Organizational Affective and Normative Commitment. International Journal of Engineering \& Technology, 7(4.15), 502-504.

https://doi.org/10.14419/ijet.v7i4.15.257 64

Khan, R., Salamzadeh, Y., Kawamorita, H., \& Rethi, G. (2021). Entrepreneurial Orientation and Small and Mediumsized Enterprises' Performance; Does "Access to Finance" Moderate the Relation in Emerging Economies? Vision-The Journal of Business Perspective, 25(1), 88-102. https://doi.org/10.1177/0972262920954 604

Mukson, M., Hamidah, H., \& Prabuwono, A. S. (2019). Entrepreneurial Orientation and Organizational Commitment in SMEs as Form of Business Performance Improvement. KnE Social Sciences/International Conference on Humanities, Education and Social Sciences (IC-HEDS), 4(14), 302-314. https://doi.org/10.18502/kss.v4i14.7888

Pratama, M. M. A., Azizah, Z., Muntarwikhi, S., W, O. D. S., Dilasari, A., Nurmawati, K. M., ... Dewi, P. T. T. (2020). Edukasi Fintech Lending Sebagai Solusi Permodalan Umkm di Masa Pandemi COVID-19 di Kecamatan Wajak Malang. Jurnal Graha Pengabdian, 2(3), 187-201.

Puente-Palacios, K., \& Souza, M. G. S. de. (2018). Professional self-concept: Prediction of teamwork commitment. Revista de Psicología, 36(2), 465-490. https://doi.org/10.18800/psico.201802.0 03

Rizianiza, I., Mungil, D., \& Idhil, A. (2021). Peningkatan Pemahaman Tentang Kemasan Pada UMKM Pengolah Rumput Laut. Jurnal ABDINUS : Jurnal Pengabdian Nusantara, 5(1), 144-152. https://doi.org/10.29407/ja.v5i1.14505

Sadough, F., \& Ebrahimi, K. (2015). Self Esteem and Organizational Commitment Among Health Information Management Staff in Tertiary Care Hospitals in Tehran. Global Journal of Health Science, 7(2), 328-334. 
https://doi.org/10.5539/gjhs.v7n2p328

Salisu, Y., \& Bakar, L. J. A. (2019). Employee Commitment to Change, Innovation Strategy and the Performance of Small and Medium Enterprises. International Journal of Business and Technopreneurship, 9(2), 123-140.

Santosa, R. M., \& Christian, M. (2017). Kencenderungan Kelompok Muda Untuk Berwirausaha Berdasarkan Faktor-faktor Personal. Jurnal Pengabdian Dan Kewirausahaan, 1(1), 56-64.

https://doi.org/10.30813/jpk.v1i1.1006

Sundara, D., Laksono, R., \& Gultom, J. R. (2020). Sosialisasi Etika Bisnis Dan Entrepreneur UMKM Setu Babakan Srengseng Sawah Jagakarsa Jakarta Selatan. Jurnal Pengabdian TERATAI, 1(2), 141-152.

Suwardi, A. B., Baihaqi, B., Syardiansah, S., \& Navia, Z. (2021). Penguatan Pemasaran Produk Tenun Lidi Nipah
Pada Kelompok Bungong Chirih Melalui Aplikasi E-Marketing Pada Masa Pandemik COVID-19. Jurnal Pengabdian Kepada Masyarakat (JPKM), 27(2), 142-146. https://doi.org/10.24114/jpkm.v27i2.195 52

Uliyandari, M., Candrawati, E., \& Latipah, N. (2021). Peningkatan Produktivitas Pupuk Kompos Bioaktivator dengan Bahan Baku Limbah Organik Rumah Tangga. Aksiologiya: Jurnal Pengabdian Kepada Masyarakat, 5(2), 203-208.

https://doi.org/10.30651/aks.v5i2.5555

Utama, G. L., Mahani, M., \& Djali, M. (2021). Skill and Knowledge Improvement Training on Honey and Propolis Commercialization in Central Bangka Regency. Engagement: Jurnal Pengabdian Kepada Masyarakat, 05(01).

https://doi.org/10.29062/engagement.v5i 1.641 